\title{
Meat and meat products: changes in demand and supply
}

By Geoff Harrington Meat and Livestock Commission, PO Box 44, Queensway House, Bletchley, Milton Keynes MK2 2EF

My brief is to talk about the changes in supply and demand. I am going to concentrate on the demand side and, in particular, the effects of adverse publicity and changing lifestyles on the demand for meat, particularly red meat, and also industry's reaction to those factors.

The proverbial 'Man from Mars', if he paid a fleeting visit, might get the impression that meat consumption is falling dramatically. One reads headlines like 'Who eats meat now?', 'Goodbye to the Sunday roast', 'New report is bad news for red meat', etc., etc. This has been the prevailing theme of media attention to the meat industry, particularly over the last 3 years.

In fact, the total consumption figures tell a rather different story. Table 1 shows that meat consumption in all its forms, when expressed in carcass weight terms, is 4 million tonnes/year in the UK. It has been rising steadily over the last few years. But what is most remarkable is the increase in domestic production. Traditionally we were the world's largest importer of meat and meat products from Australia, New Zealand and South America and parts of Europe, like Denmark. Imports have declined steadily over the last 20 years, while exports have built up to a significant amount.

If poultry is taken out, we come to a figure of between 2.93 million and 2.98 million tonnes for total red meat consumption over the last 5 or 6 years. Looking at the same information expressed in another way, in terms of per capita consumption, based on carcass weight (Table 2), we see a small decrease since the early 1970s; but the last 4 years (1985-88) have actually shown figures which are increasing, right through the period when the anti-meat publicity has raged.

Within these total figures, there is of course a difference between species; pigmeat and poultry meat have been increasing, in contrast to beef and lamb, and the swing can be entirely explained by the price differential. However, the poultry processors would no

Table 1. Trends in meat production $(P)$, imports (I), exports $(E)$ and consumption (NS) in the UK (1000 tonnes) (From Ministry of Agriculture, Fisheries and Food, and the Meat and Livestock Commission)

\begin{tabular}{|c|c|c|c|c|}
\hline Years & & $\begin{array}{c}\text { Beef, veal, } \\
\text { lamb and } \\
\text { pigmeat }\end{array}$ & Poultry & Total \\
\hline \multirow[t]{4}{*}{$1970-75$} & $\mathbf{P}$ & 2269 & 635 & 2904 \\
\hline & I & 1040 & 9 & 1049 \\
\hline & $\mathbf{E}$ & 95 & 2 & 97 \\
\hline & NS & 3211 & 643 & 3854 \\
\hline \multirow[t]{4}{*}{1987} & $\mathbf{P}$ & 2540 & 978 & 3518 \\
\hline & I & 752 & 81 & 833 \\
\hline & E & 338 & 44 & 382 \\
\hline & NS & 2992 & 1008 & 4000 \\
\hline
\end{tabular}

NS, net supplies, i.e. production plus imports less exports, adjusted for stocks. 
doubt argue that they had improved the presentation of their products more radically in response to consumer requirements, particularly in the last 5-10 years.

In the case of meat, there has been a swing from domestic to catering consumption; the reduction in canteen and institutional meals has, to some extent, been replaced by more eating out, particularly in, or from, 'fast-food' restaurants. The hamburger has also made in-roads into 'fish and chips' and a majority still claim to prefer a steak when eating out. Also, more red meat is now consumed in processed form both at home and when eating out.

Our partners within the enlarged European Economic Community have almost uniformly shown steady growth in meat consumption over the last 20 years (Table 3). France, Germany, Italy, Greece, Spain and Portugal all show increases, in contrast to the position in the USA; however, meat consumption does fluctuate much more in the USA than it does in many other countries because of supply variations. In Australia, there has been a recent decline, but from an unusually high figure in the 1970s.

Against these trends and fluctuations, the stability of consumption in the UK is remarkable. However such consumption information does not demonstrate underlying demand which is shown by the price achieved in clearing a particular level of supply.

Over the last 20 years the real price of food has been decreasing, but the real price of

Table 2. Per capita consumption of various meats in the UK ( $\mathrm{kg}$ carcass weight) (From Ministry of Agriculture, Fisheries and Food, and the Meat and Livestock Commission)

$\begin{array}{lcrrcccc}\text { Years } & \text { Beef } & \text { Lamb } & \text { Pork } & \begin{array}{c}\text { Bacon } \\ \text { and ham }\end{array} & \text { Offal } & \text { Poultry } & \text { Total } \\ 1950-54 & 17 \cdot 6 & 9 \cdot 8 & 4 \cdot 2 & 10 \cdot 3 & 1 \cdot 7 & 2 \cdot 5 & 46 \cdot 1 \\ 1955-59 & 22 \cdot 7 & 10 \cdot 6 & 8 \cdot 1 & 10 \cdot 9 & 2 \cdot 1 & 3 \cdot 8 & 58 \cdot 2 \\ 1960-64 & 22 \cdot 4 & 11 \cdot 1 & 9 \cdot 4 & 11 \cdot 5 & 2 \cdot 4 & 6 \cdot 5 & 63 \cdot 3 \\ 1965-69 & 20 \cdot 9 & 10 \cdot 5 & 11 \cdot 0 & 11 \cdot 4 & 2 \cdot 4 & 8 \cdot 8 & 65 \cdot 0 \\ 1970-74 & 21 \cdot 1 & 9 \cdot 0 & 11 \cdot 9 & 10 \cdot 8 & 2 \cdot 0 & 11 \cdot 3 & 66 \cdot 1 \\ 1975-79 & 22 \cdot 1 & 7 \cdot 4 & 11 \cdot 3 & 8 \cdot 9 & 2 \cdot 2 & 12 \cdot 4 & 64 \cdot 3 \\ 1980-84 & 19 \cdot 1 & 7 \cdot 1 & 12 \cdot 8 & 8 \cdot 6 & 2 \cdot 2 & 14 \cdot 3 & 64 \cdot 1 \\ 1985-88 & 18 \cdot 9 & 6 \cdot 6 & 13 \cdot 2 & 8 \cdot 1 & 1 \cdot 8 & 17 \cdot 2 & 65 \cdot 8\end{array}$

Table 3. Per capita consumption of red meat and poultry in countries of the European Economic Community ( $\mathrm{kg}$ carcass weight) (From Meat and Livestock Commission)

Years...

France

Belgium and

Luxembourg

West Germany

Irish Republic

Denmark

Italy

The Netherlands

Greece

UK
$1960-69$

\begin{tabular}{ccc}
\hline $\begin{array}{c}\text { Beef, veal, } \\
\text { lamb and } \\
\text { pigmeat }\end{array}$ & Poultry & $\begin{array}{c}\text { Index* } \\
59.5\end{array}$ \\
& 10.4 & 101 \\
53.3 & 7.6 & 88 \\
61.7 & 6.1 & 98 \\
52.9 & 7.2 & 87 \\
50.4 & 3.7 & 78 \\
29.3 & 8.4 & 55 \\
47.0 & 3.9 & 74 \\
27.1 & 4.5 & 46 \\
61.4 & 7.6 & 100
\end{tabular}

1985

\begin{tabular}{ccc}
\hline $\begin{array}{c}\text { Beef, veal, } \\
\text { lamb and } \\
\begin{array}{c}\text { pigmeat } \\
71.5\end{array}\end{array}$ & $\begin{array}{c}\text { Poultry } \\
17.9\end{array}$ & $\begin{array}{c}\text { Index } \\
129\end{array}$ \\
72.3 & 15.3 & 126 \\
84.1 & 9.7 & 135 \\
62.4 & 16.9 & 114 \\
71.8 & 11.0 & 119 \\
57.1 & 18.0 & 108 \\
61.0 & 13.7 & 108 \\
56.6 & 15.7 & 104 \\
53.4 & 16.0 & 100
\end{tabular}

*Expressed as \% of UK value for total meat consumption. 
Table 4. Responses to questions concerning meat-eating habits from a random sample* (\% of each sample) of adults in 4 years from 1984 to 1987 (From Gallup for Realeat Co.)

$\begin{array}{lcccc}\text { Year . . } & 1984 & 1985 & 1986 & 1987 \\ \text { ‘. avoid red meat' } & 1.9 & 2.6 & 3.1 & 3.6 \\ \text {. . vegetarian ...' } & 2.1 & 2.6 & 2.7 & 3.0\end{array}$

*Each sample approximately $\mathbf{4 0 0 0 .}$

meat has been going down faster, giving some evidence of weaker demand for meat against competing foods. This, of course, reflects the totality of factors influencing consumer demand; of these, dietary advice is but one. There are many others, particularly those to do with changing lifestyles and changing eating patterns. We are all well aware of the demise of the set meal, particularly of the Sunday roast, the increase in snacking, and the increase in the proportion of smaller families and one-parent families or one-person households where the need for convenience foods and for smaller portions is greater. All these factors work against meat as traditionally prepared and presented by the butcher.

The various kinds of adverse publicity and relevant changes in the market will now be reviewed.

The first of these concerns the extent of vegetarianism. There are two sets of information available on this subject; one is a survey carried out by Gallup and published annually by the Realeat Company, which is concerned with marketing 'Vegeburgers' (Table 4). The figures relate to $1984-87$ with a total sample of approximately 4000 adults annually, giving estimates of numbers of vegetarians rising from $2 \cdot 1$ to $3 \cdot 0 \%$ of adults. An additional $3.5 \%$ claim to avoid red meat (but presumably eat poultry or fish, or both) giving a total of $6.5 \%$ not eating red meat, which is presumably the origin of the 3 million figure for 'abstainers'.

Perceived cost may well be a factor in this. There may be a degree of overestimation from the design of the market research questions, because we have found people who have claimed to be vegetarian having stated $10 \mathrm{~min}$ earlier during the survey questioning that they regularly ate beefburgers! 'What is meat? may not be a simple question. For some people this has to be a steak, chop or stew and those things that come in buns or even sausages may be not seen as 'meat' in that context. So the answer to market research questions may be very sensitive to what the person answering believes you mean or want to know.

The second set of information comes from a continuing survey, involving 1000 people every quarter. They are asked many questions about their attitudes to food, to health and to dietary advice and well towards the end of this long questionnaire comes the question about their meat-eating habits. Table 5 shows that never, in the last 2 years, in separate quarterly reports, has the number of those claiming to be vegetarian gone above $1 \%$. In fact, the pattern is remarkably stable. For some time now $41-45 \%$ of people have been claiming they eat less meat than they used to, which in view of the total consumption figures means that the rest of us must be eating rather more!

So the two surveys, both carried out by reputable market-research companies, come up with rather different results. Nevertheless there are vegetarian influences in the market; perhaps the most important thing from the meat industry's point of view is not the number of people who for ethical or moral reasons adopt a totally vegetarian stance, but the fact that, because the food industry believes that there are more and more such people, they put on the market a range of vegetarian dishes which you do not have to be 
Table 5. Responses to questions regarding meat-eating habits from random samples* (\% of each sample) of adults in eight quarters 1985 to 1987 (From the National Health Survey)

\begin{tabular}{|c|c|c|c|c|c|c|c|c|}
\hline \multirow{2}{*}{$\begin{array}{l}\text { Year... } \\
\text { Quarter. }\end{array}$} & \multirow{2}{*}{$\begin{array}{c}1985 \\
4\end{array}$} & \multicolumn{4}{|c|}{1986} & \multicolumn{3}{|c|}{1987} \\
\hline & & 1 & 2 & 3 & 4 & 1 & 2 & 3 \\
\hline ' $\ldots$ as much as ever $\ldots$ ' & 48 & 47 & 46 & 45 & 47 & 50 & 47 & 46 \\
\hline ' $\ldots$ less than used to ...' & 41 & 43 & 43 & 45 & 44 & 41 & 42 & 44 \\
\hline ' . . only rarely . . ' & 6 & 6 & 7 & 7 & 7 & 7 & 7 & 7 \\
\hline '.. no meat but fish . . ' & 2 & 1 & 2 & 2 & 1 & 1 & 2 & 2 \\
\hline$\therefore \ldots$ vegetarian $\ldots$. & 1 & 1 & 1 & 1 & 1 & 1 & 1 & 1 \\
\hline '. . vegan . . .' & $\dagger$ & $\dagger$ & $\dagger$ & $\dagger$ & + & $\dagger$ & $\dagger$ & $\dagger$ \\
\hline
\end{tabular}

*Each sample approximately 1000 . †Negligible.

a signed-up vegetarian to eat. Many people buy these, enjoy them, and that does have an effect on the variety of their diet and their frequency of meat consumption.

A second issue has been publicity about sausages. On 5 October 1985, there was a television programme, which was not really about sausages at all. It concerned the political power of the food industry in Whitehall, and how this was used to get regulations modified or changed. The particular example of the Meat Product Regulations was cited against a background of pictures of some materials that are used in sausage manufacture-a pretty unattractive 'gunge'-and there were references to unappetizing parts of the animal which, it was claimed, went into the mincer. A lot of people thought this was very nasty and the market was hit very badly in that month and sales stayed down throughout the following year.

The problem was reinforced by a second programme in the same week on additives which used similar background pictures, coupled with the claim that additives disguise poor-quality ingredients. These programmes were extensively reviewed in newspapers with comments from the reviewer like 'Ugh, I will never eat them again'. And the subject was a matter of debate on virtually every local radio station around the country. So the spin-off publicity of those two half-hour programmes was quite dramatic.

Survey information supports this. One of the questions asked was 'What programme have you seen recently or heard recently which touched on the health issue or dietary issue?'; anyone responding to this was asked what products they had, as a consequence, bought less of. In the quarter which began on 5 October $1985,8 \%$ of people said they had seen something which put them off buying sausages. And $8 \%$ was also the market drop in domestic purchases suffered in that period.

Although this remains the subject of newspaper and magazine comment, the number of people who said their purchases have been influenced by TV or radio programmes on sausages declined to $1 \%$. This is one of the few examples where you can actually put your finger on an immediate response in the market to particular media coverage.

Germany has recently been suffering from a rather similar event to do with parasitic worms in fish. There, the market collapse has been far greater in response to certain television programmes about the infestation of the fish by some perfectly normal parasite.

In yet another survey - this is obviously very good business for market researcherswhich we do each November, we ask people whether they have heard health warnings about any particular foods (Table 6). About 20-30\% mention 'meat' without prompting; to the others we say 'here is a long list of foods, do you see any others about which you have heard health warnings?'. Then a further $40 \%$ mention meats. Then we ask these, 
Table 6. Responses to questions concerning foods about which health warnings have been heard*

\begin{tabular}{|c|c|c|c|c|}
\hline Year. . & 1984 & 1985 & 1986 & 1987 \\
\hline Spontaneous recall of warnings about meat & 20 & 31 & 21 & 25 \\
\hline $\begin{array}{l}\text { Prompted recall about meat (among a list of foods) } \\
\text { What do you recall? } \dagger\end{array}$ & 60 & 71 & 63 & 64 \\
\hline Too fatty & $241 / 2$ & 25 & $24 \frac{1}{2}$ & $261 / 2$ \\
\hline Causes heart disease & $171 / 2$ & 15 & $13^{1 / 2}$ & $161 / 2$ \\
\hline Generally bad & 11 & 11 & $11 \frac{1}{2}$ & 12 \\
\hline Hormones, antibiotics, additives & $31 / 2$ & $12 \frac{1}{2}$ & 7 & 7 \\
\hline
\end{tabular}

*Each sample approximately 2000 adults.

† Spontaneous answers, given by those recalling health warnings, etc. about meat, but expressed as percentage of total sample.

'Well, what is unhealthy about meat?' While about one-quarter of the whole sample say 'it is too fatty isn't it', quite a lot claim it causes heart disease and others say it is generally bad for you. And then there are those who mention the things that may be in meat, the additives, the hormones, the antibiotics: in $19843.5 \%$ and in 1985,1 month after those two television programmes, $12 \cdot 5 \%$ mentioned it. In 1986 and 1987 this had fallen back to $7 \%$.

This reflects another factor in the market; some people are concerned, quite rightly, about what goes into meat and what they are eating when they eat meat and meat products. But they are basing their judgement on what is good or bad very much on media comment.

A third factor affecting demand for meat is the publicity about what meat manufacturers may be up to. Manufacturers take a raw material of low value in direct use and turn it into a convenient product. They are criticized for so doing for using additives, for using salt and they are said to be 'pumping in a lot of water'.

This sort of process is increasingly described in articles in certain newspapers and magazines as product debasement and consumer deception.

One is left wondering what the consumer is supposed to do? Are you supposed to eat sirloin steak once a year, because that is all you can afford, and stewing steak infrequently because you consider it takes too much preparation time for your particular family and circumstances? You are discouraged from eating perfectly nutritious products which combine the raw material of one with the convenience and eating satisfaction of the other through the skill of the food technologist. The nutritional content of the lean meat in all three, the grilling steak, the stewing steak or the restructured steak, is essentially the same and the fat content can be controlled.

The next critical area derives, of course, from the power of dietary advice. Over the years, the basic recommendation that we should eat less fat has been interpreted in many ways; frequently 'eat less fat' has been turned into a recommendation to 'eat less meat' because red meat is thought of as a relatively fatty product. Early leaflets from some of our Health Authorities actually relegated meat to the role of flavouring.

Obviously this has produced a response from industry. The industry goes out and says to opinion-formers (writers, TV producers, those who formulate dietary advice) 'look, this is ridiculous, if you are trying to cut out fat, choose leaner meat', and presents the facts about the positive nutritional value of red meat and how low in fat lean red meat really is. The same nutritional message can be carried in consumer publicity; the notion of 'lean' goes with the concept of fitness and health. Leaflets can emphasize the positive 
nutritional virtues and how to cut down on fat and the message can be picked up in shop posters, not only to give the message to consumers but to give the man standing behind the counter renewed confidence in the product he is selling.

The industry's message is that if you are trying to reduce fat consumption and you want to carry on eating red meat then you select lean cuts, trim visible fat, grill rather than fry and so on. Instead of fried egg and bacon, with fried bread to mop up the fat, you can have wholemeal toast and grilled bacon with poached egg; such a change makes a dramatic difference to the proportion of energy from fat from that particular food combination with the same basic ingredients. Meat is sometimes criticised because it contains no dietary fibre but who eats meat on its own? You eat it with its natural accompaniments which provide the dietary fibre together with the other vitamins and minerals to complement and balance those provided by the meat.

In the current 'Look After Your Heart' campaign, lean red meat is equated with poultry and fish as foods that help in cutting down the fat; there is even an odd meat dish on the poster that goes with it. There is a direct reference to red meats in the relevant television advertizement which shows fatty bacon and fatty pork chops in a sea of fat in a frying pan replaced by lean grilled bacon and lean trimmed pork chops to contribute to what is described as a healthy meal. So we have moved a little over the last few years from red meat being cast among the real 'nasties' to avoid, to a place among the 'goodies' provided it is lean.

So what is the industry's response to that? Do they say 'buy my conventional cuts and, if you are concerned, trim the fat at home'? This does not fit in with the concept of convenience and minimal waste which is what consumers are also after. Rather you have to present progressively leaner and leaner meat for those people who are trying to cut down fat consumption. So we begin to see very lean minces, basically lean meat minced, and diced or cubed meats with all visible fat removed. In addition, of course, we have offals which are relatively low-fat and highly nutritious. We began to see a range of prepared products such as kebabs and relatively low-fat burgers and sausages with less than half the fat of the conventional recipes. So the industry can offer a range of products which meet not only the requirement for leaner meats but fit in with the requirements for convenience, minimal waste and high repeatability. All such cuts and products would qualify for identification as the 'Lean Choice'.

Last year, when we tried to persuade retailers that they should offer a range of very lean cuts; we used the term 'Super-trimmed' but we found that we were treading on the toes of some multiples and supermarket campaigns which were using phrases like extra-trim, super-trim, super-lean and so on. So this year we have chosen to encourage the concept of the 'Lean Choice'. The word 'Choice' is extremely important because it does emphasize that the industry is not pushing something down the customers' throats. They are offering a choice and butchers who display our poster guarantee to have at least six identified lean cuts on offer. We put this proposition to all the Health Authorities in England and over half the 191 have agreed to support it and put their name on the poster in the participating butchers' shops. So we actually have 'in-store' endorsement by the Health Authorities of the concept of the 'Lean Choice' with supporting labelling.

But are we ruining our product by taking off all the fat? Those who read the Farmers' Weekly will be well aware that almost every other week there are letters from farmers and butchers who believe very strongly that by pushing meat further down the leanness road we are reducing taste and eating satisfaction. Such people run 'quality' butchers' shops or farm shops where, they claim, people will drive over 50 miles to buy their meat from traditional breeds, fed traditional ways with a reasonable level of fat covering on it and products to traditional recipes. They believe lean red meat is rubbish and encourging 
its production and sale will backfire on the industry as people will find it unappetizing and bland and after a time will reject it.

In our view there is a segment of the population which is not going to eat red meat at all unless it is offered very lean, if not totally defatted, and the 'Lean Choice' range of cuts and products is designed to attract that sector of the population back to red meat. To do so does not deny that there is a continuing market for people who are offered the traditional product at traditional levels of fatness. Equally it does not mean that the people who might look for the leannest meat for normal weekly consumption will not buy something else, special Scotch Sirloin steaks, for example, for a special occasion; the principle of indulgence applies to meat as it does throughout the whole dietary spectrum.

I do not think that we can go to the extreme of saying we believe you should eat meat with fat on it because it tastes better; that really would be very bad for the industry in the current climate and a suicidal policy for the industry to adopt. The fundamental concept must be choice to suit all tastes and all preferences including dietary preferences.

What are the implications of this for production? We have calculated that, with the current populations of cattle, sheep and pigs in this country, their edible tissues consist in total of about two parts of lean meat to one part of fatty tissue. For those who are choosing lean cuts and low-fat products, we only want on average between 10 and $15 \%$ of the weight of lean meat in associated fat; so if this group grows substantially the industry has a very big problem of fat surplus to requirements. Obviously, the key issue is what proportion of the population will express a preference for the very lean product over the next few years? That we do not know. But whether that turns out to be $20 \%$ or $60 \%$, the industry clearly must continue to reduce the amount of excess fat that is already trimmed and utilized for non-edible purposes or even wasted. 